\title{
Paraspinal and Extradural Hydatid Cyst of the Spine: A Report of Three Cases and A Review of the Literature
}

\author{
Murat Çalbıyık $^{1}$, Adnan Ümit Sayar ${ }^{1}$ \\ ${ }^{1}$ Hitit University, Faculty of Medicine, Department of Orthopedics and Traumatology, Çorum, Turkey
}

Received: 14 August 2017 Accepted: 25 November 2017, Published online: 28 December 2017

(C) Ordu University Institute of Health Sciences, Turkey, 2017

\begin{abstract}
Hydatid cyst of the spine is a rare form of parasitic infection, but it is a serious clinical condition that may cause paraplegia, tetraplegia, or radiculopathy. In this report, we have presented three patients with paraspinal and extradural hydatic cysts aged 36 years, 49 years, and 66 years. Diagnoses were made using computed tomography and magnetic resonance (MR) imaging. The cysts were surgically resected and patients were given albendozole treatment postoperatively. We lost one patient during follow-up due to myocardial infarction. The other two patients had no recurrence of their hydatid cysts at six months and one year after the operation. Hydatid cyst of the spine should be considered in the differential diagnosis of patients with common symptoms of spinal cord compression. MR imaging should be performed to reach a definitive diagnosis. Hydatid cyst can only be treated by complete resection of the cysts while preventing the lesion from penetrating neighboring tissues. Antihelmintic therapy started before or after the operation and maintained further reduces the risk of recurrence.
\end{abstract}

Key words: Hydatid cyst, spine, magnetic resonance imaging, albendozole

Address for correspondence/reprints:

Murat Çalbıyık

Telephone number: +90 (532) 7698962

E-mail: drmuratcalbiyik@hotmail.com

DOI: $10.19127 / \mathrm{mbsjohs.334582}$

This study was presented orally in 8th National and 1st International Congress of Hydatidology at 13-15 April 2017 in Corum, Turkey.

\section{Introduction}

A hydatid cyst is a parasitic infection caused by the larval stage of Echinococcus granulosus and Echinococcus multilocularis, predominantly involving the liver, lungs, and brain. It is endemic to areas of the world where many people raise sheep, including the Mediterranean region (Ito and Budke, 2017). Hydatid cyst disease is a public health problem in Turkey (Turgut, 1997; Karaman et al., 2015). Bone involvement affects only $1-3 \%$ of patients with hydatid cysts, half of which have the disease in their spines (Turgut, 1997; Islekel et al., 1998). Although it is a rare form of hydatid cyst, spinal disease is a serious clinical condition that may cause paraplegia, tetraplegia, or radiculopathy (Joshi et al., 2007). Spinal instability and recurrence are common complications of hydatid cysts with vertebral involvement (Somay et al., 2014). The most common site of spinal involvement is the thoracic 
region (50\%), followed by the lumbar $(20 \%)$, sacral (20\%), and cervical regions (10\%) (Bhake and Agrawal, 2010). Hydatid disease of the spine can be classified into five types according to the location of the cyst: primary intramedullary, intradural extramedullary, extradural intraspinal, vertebral, and paravertebral (Braith and Lees, 1981). In this report, we have presented three cases of paraspinal and extradural hydatic cysts and discussed our findings in light of the current literature.

\section{Case Report}

The first case was a 36-year-old male patient who presented to our clinic with pain in the lumbar region. The patient had an L4-5-disc hernia that been operated on six years previously. He reported a history of falling from a two-meter height one year before presenting at the clinic, and he had experienced pain in his back and left sciatic nerve track since then. On physical examination, there was no pain at 30 degrees during the Laseque test and no sensory loss. His reflexes were normal. On
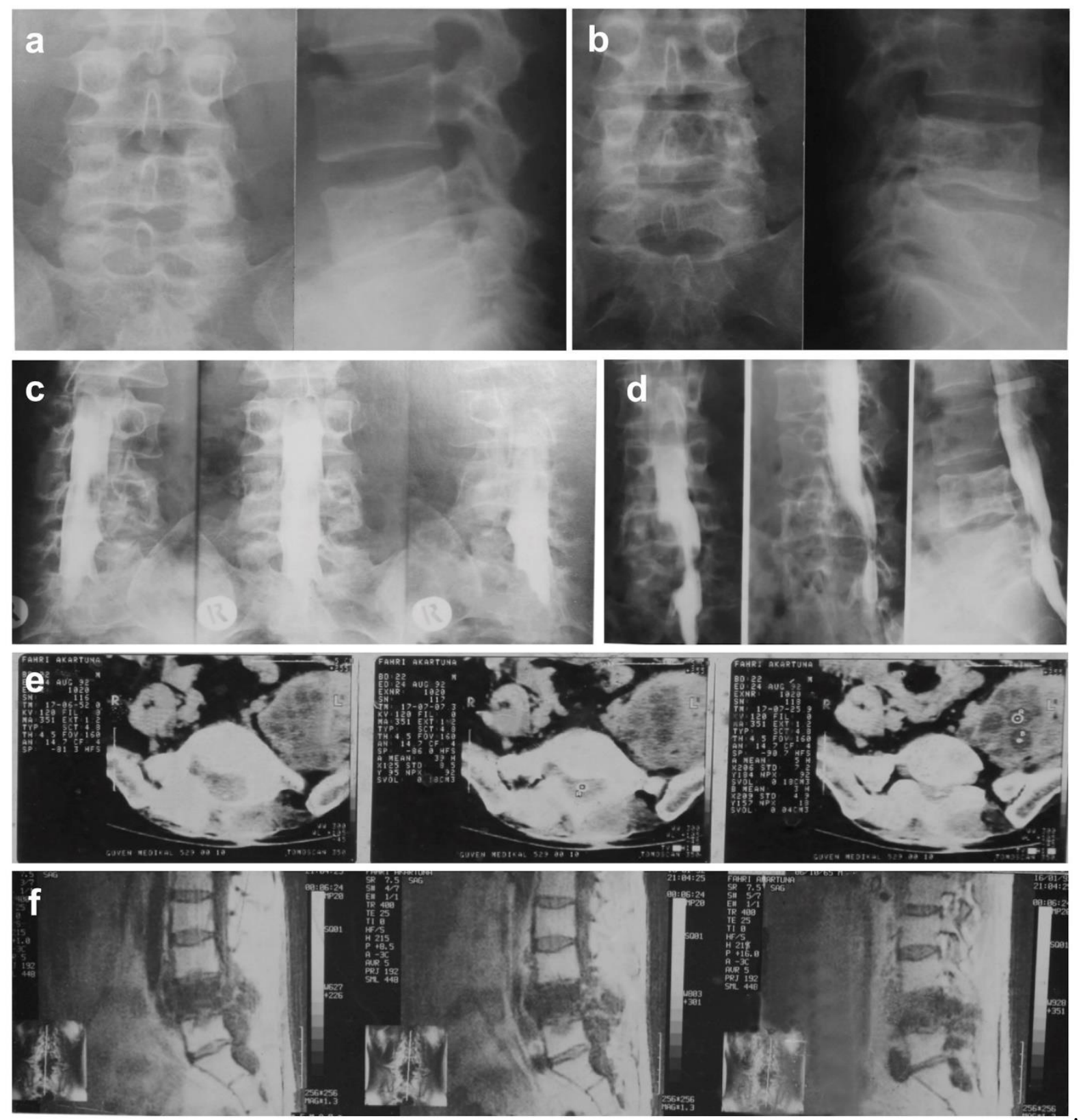

Figure 1. Preoperative X-ray (a, b), myelography (c, d), CT (e), and MR images (f) of a 36-year-old male patient with a spinal hydatid cyst. 


\section{CASE REPORT}
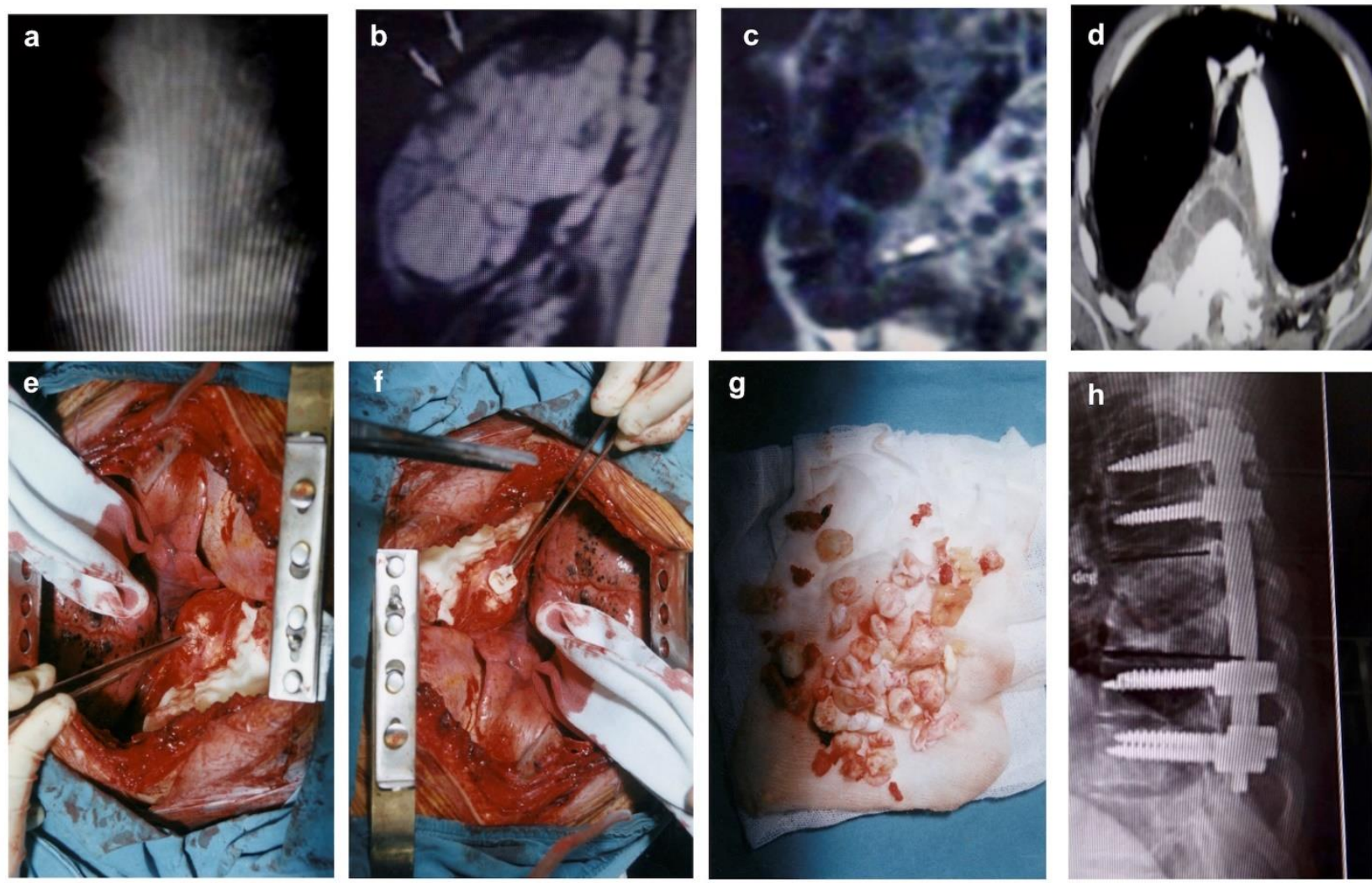

Figure 2. Preoperative X-ray (a), MR (b, c), and CT (d) images (e) of a 49-year-old male patient with a spinal hydatid cyst, who had an operation $(\mathbf{e}, \mathbf{f})$ in which the cysts were excised (g). Posterior intrumentation and fusion was performed at the T3-T8 level during the second session of surgery (h).
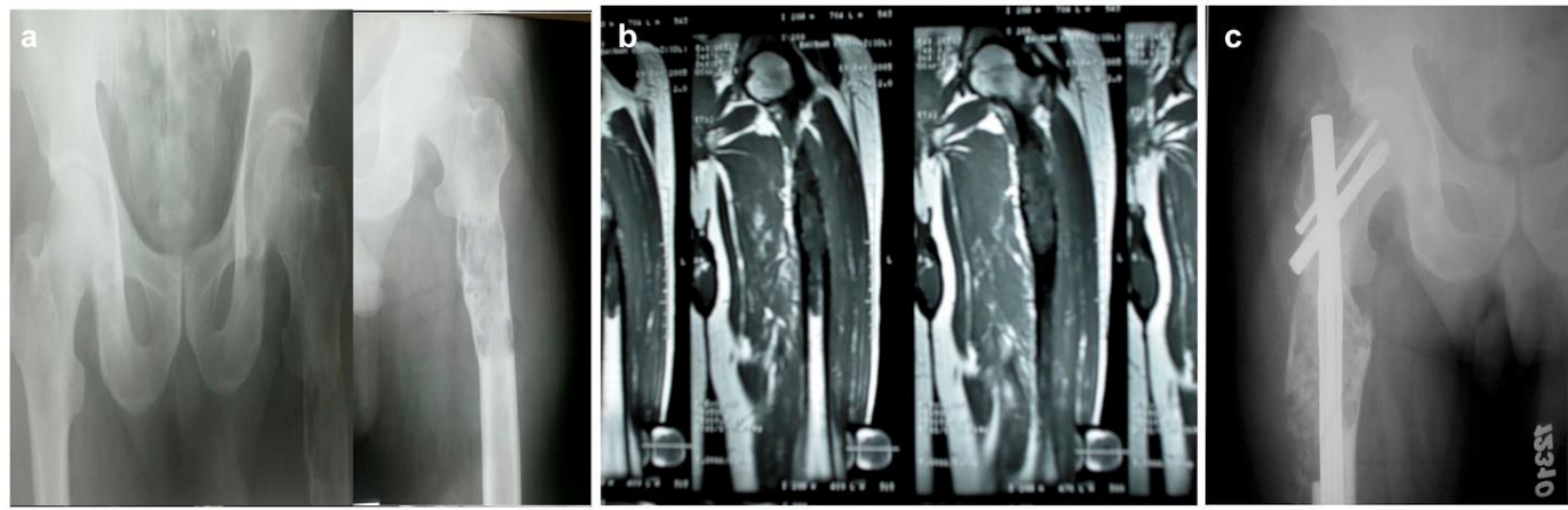

Figure 3. Preoperative X-ray (a) and MR images (b) of a 66-year-old male patient with a spinal hydatid cyst showing lytic lesions on the proximal femur in the hip joint. Postoperative X-ray image (c) showing the excised lesion and femoral nails used for fixation.

plain radiographs, irregular osteolytic lesions were detected at the L4 level. Myelography showed disc prolapsus of the operated discs. Computed tomography (CT) images showed intramedullaryextradural soft tissue lesions. On magnetic resonance (MR) images, there were multiple cystic lesions (Fig. 1). The patient was operated on while in the lateral Sims' position. Posterior laminectomy, clearance of cystic lesions, corpectomy, anterior fusion, and instrumentation were performed in this one-session operation. The patient's symptoms improved after the operation, and muscular strength returned to normal. He was given two doses of albendozole $800 \mathrm{mg} /$ day for 12 months. There was no recurrence during one-year postoperative follow-up 
The second patient was a 49-year-old male who attended to our clinic with symptoms of progressive loss of sensation and muscular strength in the lower extremities The patient was walking with a pair of armrests. Before admission to our clinic, paravertebral and extradural cystic lesions at the thoracic T5 level had been detected at another center, and the patient had refused an operation. He had been given albendozole 800 $\mathrm{mg} /$ day for two months. Preoperative studies included X-ray, myelography, CT, and MR imaging (Fig. 2). These showed cystic lesions. The patient had two operations one week apart. The first session was performed using the anteriortransthoracic approach. Hypertonic saline solution

(20\%) was injected into the cysts, and after six minutes, the cysts were excised. These were confirmed as hydatid cysts (Fig. 2). A tricortical bone graft from the iliac wing was used to reconstruct spinal defects after corpectomy. In the second session, posterior intrumentation and fusion was performed at the T3-T8 level. The patient was scheduled to continue albendozole treatment for one year. He began to walk with a single armrest at three months postoperatively. The patient died of myocardial infarction at six months after the operation.

The third case was a 66-year-old male patient who presented at our clinic with hip pain. Based on the MR images showing lytic lesions on the proximal femur in the left hip joint, the prediagnosis was aneurysmal bone cyst or hydatid cyst (Fig. 3). The patient had an operation to excise the lesions on the proximal femur, and a femoral nail was used for fixation (Fig. 3). Pathological examination of surgical specimens supported the diagnosis of a hydatid cyst. The patient was treated with albendazole $8000 \mathrm{mg} / \mathrm{day}$ for six months. In the postoperative follow-ups, union was seen, and no recurrence was detected.

\section{Discussion}

Hydatid cyst disease is a parasitic infection that affects various systems and organs of the body. Its diagnosis and treatment is difficult. Hydatid cyst disease involves the spine through vertebral-portal anastomosis (Schnepper and Johnson, 2004). Hydatid cyst of the spine is a life-threatening condition associated with high mortality and morbidity (Celik et al., 2010). Furthermore, it can persist without significant clinical symptoms, which makes diagnosis difficult. In this report, we presented three rare cases of paraspinal and extradural hydatid cyst. The primary intramedullary, intradural extramedullary, and extradural intraspinal presentations of hydatid cysts are rarer than vertebral and paravertebral disease (Onbas et al., 2004; Kahilogullari et al., 2005; Lakhdar et al., 2009). Primary intradural extramedullary hydatid cysts are an extremely rare form of parasitic infection (Kahilogullari et al., 2005; Arif and Zaheer, 2009; Lotfinia et al., 2013). In the present cases, considerably more common forms of spinal hydatid cyst (those with paraspinal, extradural, vertebral, and paravertebral involvement) coexisted.

Patients with spinal hydatid cysts are usually asymptomatic or present with compressive myelopathy or radiculopathy, with signs and symptoms varying from simple low backache to paraplegia (Joshi et al., 2007; Lakhdar et al., 2009). However, spinal hydatid cysts are often misdiagnosed, as the lesion imitates various other pathologies, such as aneurysmal bone cysts, giant cell tumors, solitary bone cysts, arachnoid cysts, neurofibromatosis, fibrocystic diseases, chondrosarcoma, and tuberculosis (Lotfinia et al., 2013; Singh et al., 2016). Since patients usually present with common signs and symptoms of spinal cord compression, diagnosis is commonly made during surgery (Pamir et al., 2002). The present cases were admitted to our clinic with back pain, loss of sensation and muscular strength in the lower extremities and hip pain, which are common symptoms of spinal cord compression.

Misdiagnosis of hydatid cysts can cause severe complications, such as rupture of the cyst and arachnoiditis (Singh et al., 2016). Therefore, clinicians should be aware of characteristic radiological signs on MR imaging with diffusionweighted images, which are cysts with thin, regular walls that look like flattened sausages without septations or debris in the lumen, and CT should be sought for correct differential diagnosis (Berk and Erdogan, 1998). On MR images, extradural cysts are usually multiple and involve the bone (Fahl et al., 1994). Lesions appear hypointense on T1-weighted images and hyperintense on T2-weighted images (Arif and Zaheer, 2009; Eksi et al., 2014). CT and MR imaging are more valuable in the diagnosis of this condition than conventional radiography (Sami et al., 1996). Sensitivity of serologic methods have been reported between $80-100 \%$ for abdominal 
disease, but $25-56 \%$ in extrahepatic involvement, which limits their use in diagnosis and follow-up of hydatid cyst of the spine (Pamir et al., 2002). The differential diagnosis includes aneurysmal bone cysts, giant cell tumors, solitary bone cysts, arachnoid cysts, neurofibromatosis, fibrocystic diseases, chondrosarcoma, and tuberculosis. In the present cases, diagnostic studies were performed using X-ray, myelography, CT, and MR imaging. Of these facilities, MR imaging provided findings most characteristic of hydatid cysts, which were multiple cystic and lytic lesions. The prediagnoses in our patients were aneurysmal bone cyst, malignancy, and disc hernia in addition to hydatid cysts.

Although hydatid cysts are symptoms of infectious disease, clinically, they behave like local malignant tumors localized in the spine. There is no generally accepted algorithm for the treatment of spinal hydatid cysts due to the limited number of cases reported in the literature. Complete resection of the spinal hydatid cyst is currently accepted as the standard treatment (Sami et al., 1996; Baykaner et al., 2000). However, surgical excision of spinal hydatic cysts is difficult due to surrounding anatomical structures and the neural foramen. In order to prevent recurrence, it is recommended that surgeons irrigate the cyst and contaminated tissues with formalin, 5\% silver nitrate, or hypertonic saline during surgery. It has been reported that the lowest concentration of hypertonic saline to be used is $20 \%$ for a duration of at least six minutes (Ozdemir et al., 2011). In the present cases, we removed the hydatid cyst surgically and applied albendozole for six months to one year postoperatively. We lost one patient during follow-up due to myocardial infarction. The other two patients had no recurrence of hydatid cysts up to one year after the operation.

\section{Conclusion}

In conclusion, hydatid cyst disease of the spine should be considered in the differential diagnosis of patients with common symptoms of spinal cord compression. A definitive diagnosis should be performed using MR imaging. Hydatid cyst disease can only be treated by complete resection of the cyst while preventing the lesion from penetrating neighboring tissues. Antihelmintic therapy started before or after surgery and maintained further reduces the risk of recurrence.
Informed Consent: Necessary information using the patient information form and consent form was taken from the patients

Peer-review: Externally peer-reviewed. Author Contributions: Concept- M.C., DesignM.C., Supervision M.C., Funding- M.C., A.U.S., Materials- M.C., Data Collection and/or Processing- M.C, Analysis and/or InterpretationM.C, Literature Review- M.C, A.U.S., WritingM.C., Critical Review- M.C, A.U.S.,

Conflict of Interest: No conflict of interest was declared by the authors.

Financial Disclosure: This research did not receive any specific grant from funding agencies in the public, commercial, or not for profit sectors.

\section{References}

Arif SH, Zaheer S. Intradural extramedullary primary hydatid cyst of the spine in a child: a very rare presentation. Eur Spine $\mathbf{J}$ 2009;18(Suppl 2):179-82.

Baykaner MK, Doğulu F, Oztürk G, Edali N, Tali T. A viable residual spinal hydatid cyst cured with albendazole. Case report. J Neurosurg 2000;93(1 Suppl):142-4.

Berk C, Ciftci E, Erdogan A. MRI in primary intraspinal extradural hydatid disease: case report. Neuroradiology 1998;40(6):390-2

Bhake A, Agrawal A. Hydatid disease of the spine. J Neurosci Rural Pract. 2010;1(2):61-2.

Braithwaite PA, Lees RF. Vertebral hydatid disease: Radiological assessment. Radiology 1981;140(3):763-6.

Celik C, Sasmaz MF, Oktay F, Ucan H, Kaptanoglu E. Paraplegia associated with spinal hydatid cyst: a case report. Spine (Phila $\mathrm{Pa}$ 1976) 2010;35(9):356-8.

Eksi MS, Bayri Y, Saracoglu A, Uyar Bozkurt S, Konya D. Primary subcutaneous hydatid cyst over throcic spine: a case report and review of the literature. Turkiye Parazitol Derg 2014;38(4):264-9.

Fahl M, Haddad FS, Huballah M, Kana'an S, Hushelmi I, Azizi T. Magnetic resonance imaging in intradural and extradural spinal echinococcosis. Clin Imaging 1994;18(3):17983. 
Islekel S, Zileli M, Ersahin Y. Intradural spinal hydatid cysts. Eur Spine J 1998;7(2):162-4

Ito A, Budke CM. The echinococcoses in Asia: The present situation. Acta Trop 2017;176:1121.

Joshi N, Hernandez-Martinez A, Seijas-Vazquez R. Primary sacral hydatid cyst. A case report. Acta Orthop Belg 2007;73(5):674-7.

Kahilogullari G, Tuna H, Aydin Z, Colpan E, Egemen N. Primary intradural extramedullary hydatid cyst. Am J Med Sci 2005;329(4):2024

Karaman U, Enginyurt O, Gurgor PN. Cystic echinicoccosis of cattle of sheep in Ordu. Middle Black Sea Journal of Health Science 2015;1(2):8-12.

Lakhdar F, Arkha Y, Rifi L, Derraz S, Ouahabi A, Khamlichi A. Spinal intradural extramedullary hydatidosis: report of three cases. Neurosurgery 2009;65(2):372-7.

Lotfinia I, Sayyahmelli S, Mahdkhah A, Shoja MM. Intradural extramedullary primary hydatid cyst of the spine: a case report and review of the literature. Eur Spine $\mathbf{J}$ 2013;22(Suppl3):329-36.

Onbas O, Kantarci M, Alper F, Sekmenli N, Okur A (2004) Spinal widespread intradural extramedullary hydatidosis. Neuroradiology 2004;46(4):310-2.

Pamir M, Zduman K, Elmaci I. Spinal hydatid disease. Spinal Cord 2002;40(4):153-60.

Sami A, Elazhari A, Ouboukhlik A, Elkamar A, Jiddane M, Boucetta M. Hydatid cyst of the spine and spinal cord. Study of 24 cases. Neurochirurgie 1996;42(6):281-7.

Schnepper GD, Johnson WD (2004) Recurrent spinal hydatidosis in North America: case report and review of the literature. Neurosurg Focus 2004;17(6):1-6.

Singh S, Sardhara J, Singh AK, Srivastava AK, Bhaisora KS, Das KK, Mehrotra A, Sahu RN, Jaiswal AK, Behari S. Spinal intradural hydatid cyst causing arachnoiditis: A rare etiology of cauda equina syndrome. J Craniovertebr Junction Spine 2016;7(4):282-4.

Somay H, Ayan E, Turk CC, Emon ST, Berkman MZ. Long-term disseminated recurrence in spinal hydatid cyst: a case report. Turkish Neurosurgery 2014;24(1):78-81.

Turgut M. Hydatid disease of the spine: A survey study from Turkey. Infection 1997;25(4):2216. 